\title{
FACTORS AFFECTING ANSERINE AND CARNOSINE LEVELS IN SKELETAL MUSCLES OF VARIOUS ANIMALS
}

\author{
ADAM A. Christman \\ Biological Chemistry Medical School, The University of Michigan, Ann Arbor, MI 48109, U.S.A.
}

(Received 3 April 1976)

\begin{abstract}
Analytical procedures for anserine, carnosine and related histidine compounds in skeletal muscles are given.

2. The anserine/carnosine ratio in the skeletal muscles of the rat increases with age, cortisone injection and lowered food intake, and in the guinea pig muscle with strenuous exercise.

3. The total anserine plus carnosine in leg muscles of the cat remain constant during long periods of deep anesthesia.

4. Skeletal muscles of man contain carnosine but no anserine. Higher levels of carnosine and low levels of anserine are found in muscles of monkey (Rhesus).

5. Carnosine but no anserine is present in leg muscles of frog.
\end{abstract}

\section{INTRODUCTION}

Carnosine ( $\beta$-alanyl-L-histidine) and anserine ( $\beta$-alanyl-L-1-methylhistidine) are found in the striated muscles of most vertebrates but are present in traces or absent in the heart and smooth muscle. A third dipeptide, balenine ( $\beta$-alanyl-L-3-methylhistidine) has been found in whale meat extract (Pocchiari et al., 1962). The structure of balenine has been verified by its synthesis (Dennis \& Lorkin, 1965). A fourth dipeptide ( $\beta$-alanyl-L-2-methylhistidine) is found in the muscles of some whales and snakes (Ona \& Hirohata, 1956). The latter dipeptide has been named ophidine but there is still some confusion as to whether the 3-methylsubstituted histidine derivative should be called ophidine or balenine. These dipeptides appear to be in a free state in the tissues, since they are readily extracted from minced muscle by hot water. Homocarnosine ( $\gamma$-amino-L-butyrylhistidine), absent in muscle tissue or found in small traces, is present in significant amounts in nervous tissue.

Many attempts have been made to correlate the levels of the imidazoyl peptides in muscle with muscular activity. The report by Johnson et al. (1967) that 3-methylhistidine is an integral part of the protein molecules of actin and myosin is of great interest. This work has been extended by others (Huszar \& Elzinga, 1971). An additional area of interest is the study of the excretion of the imidazoyl peptides and amino acids (histidine, 1-methylhistidine and 3-methyl-histidine) in relation to neuromuscular diseases.

In a comprehensive review prepared by Crush (1970) the anserine and carnosine content of the muscles of a wide variety of different animals are recorded. In most cases, however, these values came from reports in which only a few animals were used. In the present paper a more detailed study of the level of these dipeptides in various muscles of some common laboratory animals maintained under normal laboratory conditions, as well as from animals in moderate or severe stress (enforced inactivity, enforced excessive activity, thyroxin injection, cortisone injection, long periods of anesthesia (7-10 hr) with mechanical and electrical stimulation of muscles). From these studies it was hoped that some clues would be obtained concerning the metabolic role of the imidazoyl peptides.

Through the courtesy of colleagues in the medical school, I was able to obtain small samples of muscle $(10-100 \mathrm{mg})$ from University Hospital patients with a wide spectrum of medical disorders. Some were obtained by biopsy, some during surgical procedures and other post mortem. I was particularly interested to determine if the carnosine content of the muscles of patients with muscular weakness differed from those of other patients. For comparison with human muscles, samples of the Anterior tibialis muscles of five monkeys (Rhesus) were also analyzed. In addition, some preliminary studies of the muscles of the bat and frog are presented.

\section{METHODS}

The general procedures for the preparation of the deproteinized hot water extracts of muscle tissue are given in an earlier paper by Christman (1971). Some of the values for anserine, carnosine and histidine in animal muscles were obtained by the analytical procedures of this earlier paper. Since 1971, however, all of the determinations have been made on a Beckman amino analyzer (120C model) utilizing a $29 \mathrm{~cm}$ column with $22 \mathrm{~cm}$ of PA35 resin. These 
latter methods, as well as those published in 1971, employ the general techniques and reagents described by Moore et al. (1958).

In the present paper (Tables 1-3) the emphasis is on the anserine and carnosine content of muscle tissue extracts. Histidine and 1-methylhistidine are also present but in much smaller amounts. 3-Methylhistidine has not been found in any of the muscles examined to date. Method 1 (Fig. 1) requiring approx $3 \mathrm{hr}$ for completion was used for most of the analyses. Method 2 (Fig. 2), however, has been used to verify many of the results obtained by method 1. For example it was found that muscle extracts of one species of animal contained a compound not found in the standard solution, which is eluted at a time similar to that for histidinc. Since balenine added to the standard solution (Fig. 1) is eluted at the same time as histidine, a further check was needed. By procedure 2 (Fig. 2) it is noted that the peaks of elution of balenine and histidine are well separated. Re-analysis of the muscle extract by procedure 2 indicated that the extra peak was not due to balenine.

In some experiments with soft tissues, analysis by method 1, showed an elution peak just before that of $\mathrm{NH}_{4}^{+}$. This was thought to be due to 3 -methylhistidine, but reanalysis by method 2 showed it was ethanolamine. A disadvantage in the determination of both 1- and 3-methylhistidine by method 1 , if each is present in concentrations over $0.05 \mu \mathrm{mole}$, is that a single absorption peak is obtained. Their separation even at the lower concentration is sensitive to slight changes in the $\mathrm{pH}$ of the eluting buffer. Since by method 2, the elution of the 1-methylhistidine and 3-methylhistidine are well separated, experiments can be done when both are present in appreciable amounts.

The order of elution of the histidine derivatives on a $50 \mathrm{~cm}$ of amberlite IR-120 with a citrate buffer (pH 4.26, $0.38 \mathrm{M})$ at $30^{\circ} \mathrm{C}(265 \mathrm{~min})$ and for an additional $130 \mathrm{~min}$ at $50^{\circ} \mathrm{C}$ is similar to that of the present study (Zacharius \& Talley, 1962). By their system and also by method 2, $\beta$-alanyl-L-3-methylhistidine, was eluted just prior to carnosine.

Hot water extracts of skeletal muscles contain low concentrations of compounds such as ornithine, lysine and tryptophan and larger amounts of creatine which arc eluted prior to the histidine derivatives (method 1). The base line for O.D. is established after the elution of the neutral amino acids but before the elution of the compounds listed above. The ninhydrin solution $(25 \mathrm{ml} / \mathrm{hr})$ can be directed into the elution stream at $70 \mathrm{~min}$ (method 1) without risk of precipitation if the deproteinized muscle extract put on the column is equivalent to not more than $100 \mathrm{mg}$ of muscle.

Creatine, creatinine and tryptophan in concentrations found in muscle do not interfere with the determination of any of the histidine derivatives by method 2 . The ninhydrin is directed into the elution stream at approx $110 \mathrm{~min}$. If homocarnosine is present, its elution follows

Table 1. Anserine and carnosine in rat muscle (Wistar strain)

\begin{tabular}{|c|c|c|c|c|c|c|c|}
\hline \multirow[b]{2}{*}{ Sex } & \multirow[b]{2}{*}{$\begin{array}{l}\text { Rat } \\
\text { No. }\end{array}$} & \multirow[b]{2}{*}{$\begin{array}{l}\text { Age } \\
\text { (days) }\end{array}$} & \multirow[b]{2}{*}{$\begin{array}{l}\text { Wt. } \\
(\mathrm{g})\end{array}$} & \multirow[b]{2}{*}{$\begin{array}{l}\text { Muscle } \\
\text { source }\end{array}$} & \multicolumn{3}{|c|}{$\mu$ mole $/ g$ wet weight muscle } \\
\hline & & & & & Anserine & Carnosine & $\frac{\text { Anserine }}{\text { Carnosine }}$ ratio \\
\hline \multirow[t]{3}{*}{$\hat{0}$} & 1 & 35 & 100 & Left gastrocnemius & 2.6 & 4.8 & 0.54 \\
\hline & & & & Right gastrocnemius & 2.4 & 4.6 & 0.52 \\
\hline & & & & Back muscle & 3.2 & 3.8 & 0.84 \\
\hline$\hat{3}$ & 2 & 26 & 56 & Mixed leg muscles & 1.2 & 3.1 & 0.40 \\
\hline \multirow[t]{2}{*}{$\vec{b}$} & 3 & 47 & 135 & Left leg mixed muscle & 2.1 & 3.6 & 0.58 \\
\hline & & & & Right leg mixed muscle & 2.3 & 3.9 & 0.59 \\
\hline \multirow[t]{2}{*}{ 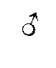 } & 4 & 120 & 325 & Left gastrocnemius & 6.8 & 3.9 & 1.9 \\
\hline & & & & Right gastrocnemius & 7.0 & 4.0 & 1.8 \\
\hline \multirow[t]{7}{*}{$\hat{\sigma}$} & 5 & 125 & 350 & Left gastrocnemius & 4.1 & 1.6 & 2.6 \\
\hline & & & & Right gastrocnemius & 4.5 & 1.8 & 2.5 \\
\hline & & & & Left tibialis anterior & 7.9 & 2.6 & 3.0 \\
\hline & & & & Right tibialis anterior & 8.3 & 2.6 & 3.2 \\
\hline & & & & Long digitali extensor & 6.0 & 1.6 & 3.8 \\
\hline & & & & Neck muscle & 2.6 & 1.1 & 2.4 \\
\hline & & & & Abdominal muscle & 7.1 & 2.3 & 3.1 \\
\hline$\hat{d}$ & 68 & 425 & $\begin{array}{c}516 \\
544 \\
\text { mean } 531\end{array}$ & $\begin{array}{l}\text { Gastrocnemius, soleus, } \\
\text { plantaris group }\end{array}$ & $\begin{array}{c}6.8-8.5 \\
\text { mean } 7.5\end{array}$ & $\begin{array}{c}1.1-1.3 \\
\text { mean } 1.2\end{array}$ & 6.2 \\
\hline$q$ & $9-14$ & 60 & $\begin{array}{c}173- \\
192 \\
\text { mean } 182\end{array}$ & & $\begin{array}{c}1.6-2.7 \\
\text { mean } 2.2\end{array}$ & $\begin{array}{l}2.0-3.2 \\
\text { mean } 2.5\end{array}$ & 0.9 \\
\hline 7 & $15-17$ & 425 & $\begin{array}{c}272- \\
303 \\
\text { mean } 291\end{array}$ & & $\begin{array}{l}6.2-8.2 \\
\text { mean } 7.1\end{array}$ & $\begin{array}{l}1.7-2.5 \\
\text { mean } 2.1\end{array}$ & 3.4 \\
\hline
\end{tabular}

Histidine ( $\mu \mathrm{mole} / \mathrm{g}$ of wet muscle) was found in all of the muscles in amounts of $0.2-0.5 \mu$ mole with an average value of approx $0.3 \mu \mathrm{mole} / \mathrm{g}$.

In many experiments a portion of the muscle was used for water content. Values fell in the range $73.77 \%$ with most at the $75 \%$ level. 
Table 2. Influence of hydrocortisone on the level of anserine and carnosine in striated muscles (gastrocnemius, tibialis and plantaris group) of the rat. ${ }^{a}$ All values are means \pm S.E. Number of rats per group given in parentheses

\begin{tabular}{|c|c|c|c|c|c|}
\hline $\begin{array}{c}\text { Group } \\
\text { No. }\end{array}$ & Treatment & $\begin{array}{c}\text { Change } \\
\text { in weight } \\
(\%)\end{array}$ & \multicolumn{2}{|c|}{$\mu \mathrm{mole} / \mathrm{g}$ of wet muscle } & $\begin{array}{l}\text { Anserine } \\
\text { Carnosine }\end{array}$ \\
\hline 1 & Control ad lib. (11) & +34 & $3.90 \pm 0.13$ & $3.83 \pm 0.15$ & $1.03 \pm 0.04$ \\
\hline 2 & Control, pair fed ${ }^{b}(6)$ & -20 & $4.52 \pm 0.12^{c}$ & $2.60 \pm 0.11^{e}$ & $1.75 \pm 0.11^{\circ}$ \\
\hline 3 & Hydrocortisone $(6)$ & -19 & $5.23 \pm 0.22^{d}$ & $1.27 \pm 0.05^{f}$ & $4.20 \pm 0.11$ \\
\hline 4 & Hydrocortisone (6) & -27 & $5.00 \pm 0.35$ & $1.23 \pm 0.07$ & $4.07 \pm 0.13$ \\
\hline 5 & Adrenalectomized (6) & +21 & $3.80 \pm 0.14$ & $3.33 \pm 0.19$ & $1.15 \pm 0.07$ \\
\hline
\end{tabular}

a Sprague-Dawley strain of Wistar rat.

${ }^{b}$ Pair-fed with hydrocortisone-treated rats (group 3). Groups 1, 3, 4 and 5 fed ad lib.

${ }^{c} P<0.01$ vs control ad lib. (group 1).

${ }^{d} P<0.02$ vs control fed (group 2).

${ }^{\circ} P<0.001$ vs control ad lib. (group 1).

${ }^{f} P<0.001$ vs control fed (group 2).

that of carnosine after the passage of an additional $15 \mathrm{ml}$ of $\mathrm{pH} 4.26$ buffer.

\section{RESULTS}

One phase of this work was undertaken to determine why the values reported by different workers for the anserine and carnosine of a specified muscle of one animal species showed such wide variations. Is it possible that during the time the muscle is removed and homogenized or finely minced, prior to hot water extraction and deproteinization, that enzymatic action on the dipeptides has occurred? To check this point the gastrocnemius muscle of the left leg of a rat under deep anesthesia was excised as rapidly as possible, weighed, homogenized, extracted with hot water and deproteinized. Thirty minutes later the gastrocnemius of the right leg was treated in the same way. The anserine and carnosine content of the deproteinized extracts calculated as $\mu$ mole per $\mathrm{g}$ of wet muscle are in good agreement. The results given in Table 1 (rats 1,3,4 and 5) are typical and do not point to a loss or interconversion of 2 peptides during the early stages of analysis.

Values for anserine and carnosine (Table 1) of the gastrocnemius muscles of the rat (1-4 and 5) show a wide variation. The excised muscles were freed of any obvious collagen and fatty material before the muscle was weighed for analysis. Although rats 4 and 5 are approximately the same age and weight, the

Table 3. The anserine and carnosine content of cat muscle

\begin{tabular}{|c|c|c|c|c|c|c|}
\hline \multirow[b]{2}{*}{ Cat } & \multirow[b]{2}{*}{ Hours $^{a}$} & & \multicolumn{3}{|c|}{$\mu$ mole $/ \mathrm{g}$ wet muscle } & \multirow[b]{2}{*}{$\begin{array}{l}\text { Anserine } \\
\text { Carnosine }\end{array}$} \\
\hline & & Muscle & Anserine & Carnosine & $\begin{array}{c}\text { Carnosine } \\
\text { plus anserine }\end{array}$ & \\
\hline \multirow[t]{3}{*}{1} & \multirow[t]{3}{*}{0} & Gastrocnemius & 10.1 & 6.5 & 16.6 & 1.5 \\
\hline & & Tibialis anterior & 14.2 & 14.0 & 28.2 & 1.0 \\
\hline & & Plantaris & 11.9 & 7.9 & 19.8 & 1.5 \\
\hline \multirow[t]{3}{*}{2} & \multirow[t]{3}{*}{0} & Gastrocnemius & 14.2 & 2.2 & 16.4 & 6.5 \\
\hline & & Tihialis anterior & 17.7 & 10.6 & 28.3 & 1.7 \\
\hline & & Plantaris & 14.8 & 4.0 & 18.8 & 3.7 \\
\hline \multirow[t]{4}{*}{3} & \multirow[t]{4}{*}{7} & Gastrocnemius & 13.7 & 4.4 & 18.1 & 3.1 \\
\hline & & Tibialis anterior & 16.4 & 11.1 & 27.5 & 1.5 \\
\hline & & Biceps & 11.7 & 5.3 & 17.0 & 2.2 \\
\hline & & Triceps & 12.3 & 3.5 & 15.8 & 3.5 \\
\hline \multirow[t]{4}{*}{4} & \multirow[t]{4}{*}{10} & Knee flexor & 8.4 & 10.7 & 19.1 & 0.8 \\
\hline & & Knee extensor & 7.6 & 6.5 & 14.1 & 1.2 \\
\hline & & Biceps & 9.2 & 7.5 & 16.7 & 1.2 \\
\hline & & Triceps & 7.6 & 7.6 & 15.2 & 1.0 \\
\hline \multirow[t]{4}{*}{5} & \multirow[t]{4}{*}{8.5} & Knee flexor & 6.5 & 14.7 & 21.2 & 0.4 \\
\hline & & Knee extensor & 8.0 & 15.5 & 23.5 & 0.5 \\
\hline & & Biceps & 8.1 & 8.6 & 16.7 & 0.9 \\
\hline & & Triceps & 8.2 & 9.3 & 17.5 & 0.9 \\
\hline
\end{tabular}

${ }^{a}$ The cats were anesthetized with pentobarbital $(35 \mathrm{mg} / \mathrm{kg}$ ). The figures in column 2 represent the number of hrs (after deep anesthesia was established) before muscle samples were obtained. 


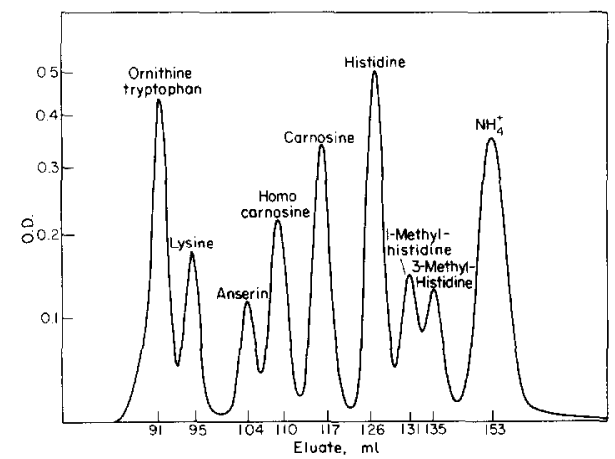

Fig. 1. Resolution on a $22 \mathrm{~cm}$ column of Resin PA35 at $40^{\circ} \mathrm{C}$ for $1 \mathrm{hr}$, then $55.6^{\circ} \mathrm{C}$. Sodium citrate buffer $(0.35 \mathrm{M}$, $\mathrm{pH} 5.26-5.27$ ) at $40 \mathrm{ml} / \mathrm{hr}$ for $30 \mathrm{~min}$, then $50 \mathrm{ml}$ per hr. $\mu$ Moles, ornithine 0.1 , tryptophan 0.1 , lysine 0.05 , anserine 0.1 , hemocarnosine 0.1 , carnosine 0.2 , histidine $0.2,1$-methylhistidine 0.05, 3-methylhistidine $0.05, \mathrm{NH}_{4}^{+} 0.15$.

anserine and carnosine content of their gastrocnemius muscles vary widely. The same is true for the values found in the literature for the content of these dipeptides in the gastrocnemius muscle of the white rat.

Davey (1960) has commented on the constancy of the anserine and carnosine content of a specific muscle of one species. He reports a value of $6.7 \mu$ mole of anserine per $\mathrm{g}$ of gastrocnemius muscle of white rat but an absence of carnosine. Crush (1970) obtained values of $7.0 \mu \mathrm{mole}$ of anserine and $2.5 \mu$ mole of carnosine per $\mathrm{g}$ of a mixed muscle sample of the rat. The results given in Table 1 represent typical values from a large number of analyses for the anserine and carnosine content of the striated muscles of the white rat. Many of them were made on samples of mixed muscles. Although there were wide variations in the ratios of anserine and carnosine, in none was there a complete absence of carnosine.
In Table 1 there is one consistent point, viz., that the muscles of the younger rats (males 1-3) and females (9-14 inclusive) have an anserine content less than that of carnosine. In contrast the muscles of the older animals (males 5-8, and females 15-17) have an anserine/carnosine ratio greater than 1.0. This ratio is particularly high for the older, heavier males (6-8).

In 1968, Drs. B. J. Cohen and D. B. Feldman of the Animal Research Center of the University of Michigan were engaged in a study of the relation of the weight of some tissues (thyroid, thymus, pituitary and adrenals) of the white rat to their overall activity (unpublished data). Eight of the group were confined in small cages which permitted minimum activity and 9 were kept in larger cages with exercise wheels equipped with revolution counters. Four of each group received a daily intraperitoneal injection of $10 \mu \mathrm{g}$ of L-thyroxin. The remaining rats of the group received a daily injection of the L-thyroxin carrier solution. The experiment was terminated when the rats were from 101 to 103 days of age. Through the courtesy of the above workers the gastrocnemius muscles of these rats were made available to the author. The mean anserine values in $\mu$ mole/g of muscle for groups (a) rats with limited activity, (b) rats with limited activity receiving thyroxin, (c) rats allowed more activity, (d) rats allowed more activity receiving thyroxin were 7.45 (S.E. \pm 0.64 ), 7.45 (S.E. \pm 0.52 ), 6.7 (S.E. \pm 0.44 ) and 7.2 (S.E. \pm 0.64 ), respectively. The corresponding mean values for carnosine were 3.7 (S.E. \pm 0.43 ), 3.8 (S.E. \pm 0.17 ), 3.4 (S.E. \pm 0.32 ) and 3.1 (S.E. \pm 0.46 ), respectively. From these values it can be concluded that neither the degree of activity of the rats or stimulation by thyroxin injections had any effect on the anserine and carnosine levels in the gastrocnemius muscle. As measured by the revolution counter, the exercise taken by individual rats varied widely.

Since this group of 17 rats was grown under controlled conditions from birth to death, the analytical

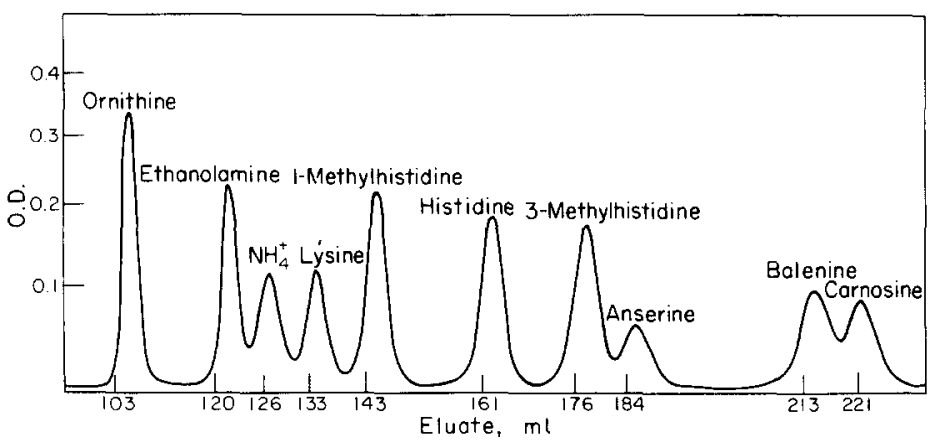

Fig. 2. Resolution on a $22 \mathrm{~cm}$ column of resin PA35 at $40^{\circ} \mathrm{C}$ for $200 \mathrm{~min}$, then $55.6^{\circ} \mathrm{C}$. Sodium citrate buffer $(0.38 \mathrm{M}, \mathrm{pH} 4.264 .28)$ at $40 \mathrm{ml} / \mathrm{hr}$ for $30 \mathrm{~min}$, then $50 \mathrm{ml} / \mathrm{hr}$. $\mu$ Moles: ornithine 0.1 , ethanolamine $0.17, \mathrm{NH}_{4}^{+} 0.05$, lysine $0.05,1$-methylhistidine 0.1 , histidine $0.1,3$-methylhistidine 0.1 , anserine 0.1 , balenine 0.1 , carnosine 0.1 . 
results are worthy of comment. The mean anserine concentration in moles per $\mathrm{g}$ of muscle (wet weight) was 7.0 with $12-17$ values falling in the range of $7.0 \pm 1.0$. The mean value for carnosine per $g$ was $3.5 \mu$ moles with $13-17$ values in the range of $3.5 \pm 0.7$. These results are in good agreement with those for the gastrocnemius muscle of rat 4 (Table 1) of approximately the same age and weight.

The data from a Japanese laboratory have been interpreted by the author Nagai (1971) as evidence that carnosine is a co-factor in the defensive action of cortisones. An experiment was planned in cooperation with Dr. Burton Baker of the Department of Anatomy at the University of Michigan to see if the administration of hydrocortisone to rats would change the levels of anserine and carnosine in a typical group of muscles (gastrocnemius, soleus, plantaris). Rats at the age of 60 days weighing from 234 to $288 \mathrm{~g}$ at the beginning of the experiment were sacrificed 19 days later. The muscle group of one leg was used for the determination of anserine, carnosine and other histidine derivatives and the alternate leg muscle for water content which for the 35 rats ranged between 74 and $78 \%$.

Rats in groups 3 and 4 (Table 2) received $5 \mathrm{mg}$ of hydrocortisone acetate per day for 18 days by subcutaneous injection. Rats in groups 1 and 2 received daily subcutaneous injections of the cortisone carrier solution. Rats in group 5 were adrenalectomized on the first day of the experiment and were fed ad lib. throughout the experimental period. Since the rats receiving the hydrocortisone lost weight during the experiment, rats of group 2 (control), were pair fed with rats of group 3 .

From Table 2 it can be seen that hydrocortisone increased the anserine level and lowered the carnosine level and thus increased the anserine/carnosine ratios as compared to the control rats. The rats at sacrifice were 79-80 days of age and the anserine/carnosine ratios of the muscles of the rats of group 1 are characteristic for that age group. Only part of the change of the anserine and carnosine content of the muscles of rats of groups 3 and 4 can be attributed to the hydrocortisone treatment which resulted in decreased food intake and weight loss. The effect of food restriction alone is shown by comparison of values obtained for rats of group 2 compared to group 1. However, the steroid had highly significant effects beyond those due to food restriction as seen by a comparison of the group of hydrocortisone treated rats with their pair-fed controls (group 3 as compared to group 2).

The second hydrocortisone-treated group (group 4) gave the same results as did the first group (group 3). Adrenalectomy had no significant effect on the anserine and carnosine levels (group 5 vs groups 1). The increase in the ratio of anserine/carnosine in the muscles of the rats receiving cortisone might be interpreted as an indication that in the presence of cortisone, carnosine was being utilized for some metabolic role. More simply it might be concluded that corti- sone favored the methylation of carnosine. It should be noted that the level of anserine plus carnosine is definitely lower in the muscles of the rats receiving cortisone. The histidine content of the muscles was essentially the same for all groups $(0.2 \pm 0.1 \mu \mathrm{mole} / \mathrm{g})$. Traces of 1-methylhistidine were found in all of the muscles but 3-methylhistidine was absent.

In the review article by Crush (1970) no values are given for the anserine and carnosine content of the muscles of the guinea pig (Cavia parcellus) commonly used in laboratory studies. Faulkner and his associates (1972) have been engaged in a study of the histological changes in guinea pig muscle in relation to age and exercise. The gastrocnemius muscles of 8 guinea pigs were made available for the present study. Five of these samples were taken from non-exercised control animals. The anserine in $\mu$ mole $/ \mathrm{g}$ of these animals was $4.2,3.0,2.6,2.9$, and 2.7 . The corresponding carnosine values in $\mu$ moles were $0.7,0.6,0.5,0.5$, and 0.6 . The muscles of the 2 guinea pigs which were removed directly after prolonged exercise had 4.2 and $3.3 \mu$ moles of anserine per $g$ but not a trace of carnosine. One additional guinea pig was subjected to the same prolonged treadmill exercise but the muscle sample was not removed until after a short period of rest. This muscle contained 3.9 and $0.5 \mu$ moles of anserine and carnosine per $\mathrm{g}$ respectively. Insufficient data are at hand to draw any conclusions, but the shift of carnosine to anserine appears to be associated with strenuous exercise.

The histidine content of the guinea pig muscles ranges from 0.1 to $0.3 \mu \mathrm{mole} / \mathrm{g}$. 1-Methylhistidine was present at a somewhat lower concentration ranging from 0.05 to $0.20 \mu \mathrm{mole} / \mathrm{g}$ of muscle. Another small peak coming between that of 1-methylhistidine and $\mathrm{NH}_{4}^{+}$was thought to be 3-methylhistidine. Repetition of the analysis by the procedure utilizing the $\mathrm{pH} 4.26$ buffer $(0.38 \mathrm{~N})$ indicated, however, that the peak was due to ethanolamine and not 3-methylhistidine.

Crush (1970) reported $17.6 \mu$ moles of anserine and $9.7 \mu$ moles of carnosine per $\mathrm{g}$ of cat muscle. These values are definitely higher than those of Tallan et al. (1954) of $8.3 \mu$ moles of anserine and $6.6 \mu$ moles of carnosine per $\mathrm{g}$. Two full-grown cats were anesthetized and the gastrocnemius, tibialis anterior, and plantaris muscles were removed at once for analysis (Table 3). The amounts of anserine and carnosine differ from muscle to muscle. Although the concentrations of anserine and carnosine for the 3 muscles of cat 1 are not the same as for cat 2, the total of the 2 dipeptides per $g$ of muscle agree very well. If the anserine/carnosine ratios are calculated, it will be noted that in each of the 3 muscles, the ratio is higher for cat 2 than cat 1 . No data were available on the age of the cats but our work on rats indicated that the higher ralios were characteristic of the muscles of old rats.

During the summer of 1974, Dr. Casey and coworkers of the Department of Physiology, University of Michigan, were engaged in a study of the response 
of the brain and spinal cord of cats in deep anesthesia (pentobarbital, $35 \mathrm{mg} / \mathrm{kg}$ ) to electrical and mechanical stimulation applied to their hind legs. Some typical muscles of the fore and hind legs of 3 of these cats (3-5-Table 3) were obtained for analysis. The muscles of cat 3 and cat 4 were obtained after 7 and $10 \mathrm{hr}$, respectively of deep anesthesia and intermittent stimulation of the hind legs. The total anserine plus carnosine per $\mathrm{g}$ of the gastrocnemius and tibialis anterior muscles of cat 3 do not differ appreciably from those of cat 1 and cat 2 in spite of the $7 \mathrm{hr}$ period of anesthesia and stimulation. Although cat 4 was subjected to an additional 3 hours of testing, the total of the 2 dipeptides per $g$ in the biceps and triceps muscles of cats 3 and 4 was essentially the same.

The spinal cord of cat 5 was cut in the lumbar region after deep anesthesia was established. The hind legs were stimulated as previously described for $8.5 \mathrm{hr}$ before the experiment was terminated. It is of interest that the total content of anserine plus carnosine per $\mathrm{g}$ of the biceps and triceps muscle is in good agreement with the values for the same muscles of cats 3 and 4 . It was thought that the knee flexor and knee extensor muscles of cat 5 , due to the paralysis caused by lumbar section of the spinal cord, might have a lower content of anserine plus carnosine. The values are actually higher than those for the same muscles of cat 4. It should be pointed out, however, that although cat 5 has lost its ability to move, there was considerable contraction of the hind legs due to reflex action. Typical muscles from the hind legs of more control animals and more after lumbar section must be analyzed before any conclusions can be drawn. It should be noted, however, that for each muscle there appears to be a rather constant value for the sum of the anserine and carnosine regardless of their individual concentrations.

Through the courtesy of Dr. James Koski (Department of Anatomy, University of Michigan) who has made some interesting studies on bats (Myotis sodalis) entering into and emerging from hibernation, we were able to obtain 2 samples of the pectoral muscles. One was from a bat maintained at room temperature and the second from one kept at a low temperature to induce hibernation. It was surprising to find that neither anserine or carnosine were present. These were the first samples of skeletal muscles, analyzed in this laboratory, in which both dipeptides were absent. It is hoped that the pectoral muscles of other species of bat can be obtained for analysis.

The early interest of the author in the anserine and carnosine of muscle was stimulated by the early observation of Tallan (1955) that the skeletal muscles of rabbits maintained on diets deficient in vitamin $E$ had a lowered content of these dipeptides. Even though the type of muscular dystrophy induced in rabbits on such diets is not the same as that in muscular dystrophy in humans, it was of interest to see if the muscles of individuals with various types of muscular weakness differed from those of normal human subjects in their content of the two dipeptides. Very little data was found in the article of DuVigneaud \& Behrens (1939) on this subject. Perry et al. (1967) reported $2.89 \mu$ moles of carnosine and no anserine per $\mathrm{g}$ of subscapularis muscle obtained at autopsy from an adult woman.

With the cooperation of Dr. Abrams of the Department of Pathology, University of Michigan, 18 samples of human skeletal muscle (Psoas) were obtained at autopsies done at intervals ranging from 2 to $26 \mathrm{hr}$ after death. The cause of death of these subjects was variable (accidents, gunshot wounds, heart failure, pneumonia, renal failure, etc.). The carnosine per $\mathrm{g}$ of wet muscle ranged from 1.0 to $7.7 \mu$ mole but anserine was absent or present only in traces. The lowest level of carnosine was from the muscle of a man 88 years of age and the highest level from a girl of 16 years. There appeared to be no correlation between the carnosine levels and the elapsed time between death and the receipt of the muscle sample. Although anserine incubated with homogenates of human muscle at $37^{\circ} \mathrm{C}$ for several hours could be fully recovered, the possibility that the absence of anserine in human muscle was due to enzymatic breakdown prior to analysis had to be considered.

Permission was obtained for the study of human muscles if samples taken for biopsy or incident to surgery were available. These samples of striated muscle ranging in weight from $10 \mathrm{mg}$ to $1 \mathrm{~g}$ (usually $10-50 \mathrm{mg}$ ) were dropped in dry ice on removal, weighed, and the analysis started immediately. Over a period of 6 years, 28 samples of striated muscles were obtained from individuals, male and female, in the age group of 5 months to 80 years. Many of the samples were obtained through the courtesy of Dr. W. Smith (Department of Surgery, University of Michigan) from subject undergoing bone and joint repair. Five of the highest values for carnosine $(6.1$, $6.6,4.9,6.4,8.3 \mu \mathrm{mole} / \mathrm{g}$ ) for this group of patients were from individuals in the 14-18 age group. The lowest values (1.0 and $1.5 \mu \mathrm{mole} / \mathrm{g}$ of Vastus lateralis) were from a female of 62 years of age and a male of 80 years of age, both of whom had been immobilized for some time following fracture of the hip.

An effort was made to obtain muscle samples from persons with muscular dystrophy or other diseases characterized by muscular weakness. Unfortunately only a few samples were made available for study. A sample of the thigh muscle of an adult paraplegic patient had a low carnosine content $(1.0 \mu \mathrm{mole} / \mathrm{g})$. A 43 year old patient in the hospital because of progressive muscular weakness had a carnosine level of $4.8 \mu \mathrm{mole} / \mathrm{g}$ of muscle. The histological and histochemical studies, however, indicated that the muscle (Vastus lateralis) was normal. A 2 year old female patient with muscular paralysis due to poor innervation had a muscle carnosine level of $2.8 \mu \mathrm{mole} / \mathrm{g}$. This is not low for this age group since 2 additional 
patients without muscular dysfunction had muscle carnosine values of 1.8 and $2.3 \mu \mathrm{mole} / \mathrm{g}$. The muscle (Vastus lateralis) of a 11 year old female patient with a 5 year history of muscular weakness was studied by histological and histochemical methods and diagnosed as characteristic of muscular dystrophy. The corresponding muscle of her mother ( 45 years of age) who also suffered from muscular weakness was examined by the same methods and reported to be normal. The level of carnosine $(2.0 \mu \mathrm{mole} / \mathrm{g})$ in the muscle of the mother is somewhat lower than normal but that of her daughter $(4.2 \mu \mathrm{mole} / \mathrm{g})$ is certainly in the normal range. In none of the samples taken during the course of surgery or by biopsy was there any indication of more than a trace of anserine in human muscle. The content of histidine in the hot water extracts of human muscle was usually about $1 / 20$ that of the carnosine.

A few muscle samples were obtained from monkeys (Macaeus rhesus), which were part of a colony used by the Department of Pharmacology for a study of drug addiction. In all but one case the drug that was used was shown to be non-addicting. From $40-300 \mathrm{mg}$ of muscle (Anterior tibialis) was removed from the anesthetized animal. None of the 5 monkeys had received any drug in the 40 days prior to removal of the muscle. The drug had not been given to the addicted monkey for 60 days prior to this experiment. The carnosine levels of the 5 muscles $(\mu \mathrm{mole} / \mathrm{g}$ ) were $17.1,17.9,18.3,18.6$ and 23.4 and in the same order the anserine values were $0.34,0.35,0.71,0.41$ and $0.49 \mu$ mole. The values for anserine in the muscles of the monkey are low compared to that of most mammalian striated muscle but there were definite elution peaks. The carnosine values obtained in this study are similar to those reported in the paper of DuVigneaud \& Behrens (1939). In the review article by Crush (1970) the leg muscles of the Patas monkey was reported to contain $3.6 \mu$ mole of carnosine per $\mathrm{g}$ of muscle but no anserine. The Owl monkey on the other hand had $4.0 \mu$ mole of anserine and $0.1 \mu$ mole of carnosine per $\mathrm{g}$ of leg muscle.

Severin and Vulfson (1963) have reported that the sartorius muscle of the frog contracts more strongly and for a longer period of time in Ringers solution containing carnosine than in the standard Ringers solution. This was ascribed to the role of carnosine acting on muscle endplates in a mediator mechanism of neuromuscular transmission. To support this theory these authors have presented evidence that the levels of carnosine in the sartorius and gastrocnemius muscles of the frog are higher in those areas, which are more highly innervated. In the sartorius muscle of the frog this area is the central cross-section and in the gastrocnemius muscle the proximal cross-section.

The muscles of 5 leopard frogs (Rana pipiens) were analyzed by method 1 . These muscles included the total leg muscles from ankle to knee and knee to hip as well as proximal, middle and distal cross sections of these muscles. In addition the sartorius and gastrocnemius muscles as well as the 3 cross-sections of these muscles were analyzed. Anserine was absent or present in small traces in all of these muscles. The values for carnosine varied from 4.0 to $15.4 \mu \mathrm{mole} / \mathrm{g}$ of muscle.

The free histidine content of frog muscle as determined by method 1 is definitely higher than that previously found for the muscles of other animals $(0.5-2.0 \mu \mathrm{mole} / \mathrm{g}$ as compared to $0.1-0.5 \mu \mathrm{mole} / \mathrm{g}$ for rats, cats, guinea pig and man). Re-analysis of the deproteinized, hot water extracts of frog muscle by method 2, gave values for both carnosine and histidine which were from 30 to $40 \%$ lower than those of method 1. In our previous work with muscles of other animals, results by the 2 methods usually gave values that were within $1-3 \%$ of each other.

A careful inspection of the elution profiles of the 22 analyses of frog muscle by method 1 did show, however, that the carnosine elution curve was not symmetrical but slightly shifted to the right toward the histidine elution area. The deviation was so small that it was detected only by careful measurement. Analysis of these samples by method 2, however, gave symmetrical elution curves for both histidine and carnosine. Obviously the second method of analysis resolves the discrepancy and causes the interfering compound to elute at a different location. Work at present time is directed toward the determination of the compound or compounds in frog muscles that are eluted with carnosine and histidine by the method 1 procedure.

When balenine is added to the standard solution used in the preparation of Fig. 1 (method 1) it is eluted in the same area as carnosine and histidine. Figure 2 shows that by method 2 balenine is eluted just prior to carnosine. The unknown material in muscle extract of frog (Rana pipiens) is not balenine, however, since we did not observe an elution peak just before the carnosine when method 2 was used.

The deproteinized hot water extracts of the bull frog (Rana catesbina) contain a compound, which by method 1 is eluted at a time predicted for carnosine (Fig. 1). The elution area has a wide spur to the right covering the area for histidine elution. Re-analysis by method 2 gives a small symmetrical peak for histidine but a broad irregular peak in the area of carnosine elution. It is possible that balenine may be responsible for this fused peak with carnosine. Sufficient eluate from this area must be obtained to determine whether acid hydrolysis will yield 3-methylhistidine, which would indicate balenine.

The experiments with frogs (Rana pipiens) were designed to re-examine the work of Severin \& Vulfson (1963) with reference to the distribution of carnosine in various cross-sections of the gastrocnemius and sartorius muscles. Unfortunately since many of the cross-sections of the individual muscles were small $(10-20 \mathrm{mg})$ we had to use the entire sample for analysis by method 1 and the correct values for carnosine obtainable by method 2 are not available. 
Ethanolamine is present in appreciable amounts in frog muscle, in smaller amounts in the guinea pig muscle and in trace amounts in the muscles of other animals. The elution of ethanolamine by both methods occurs just before that of $\mathrm{NH}_{4}^{+}$. By method 1 , however, its elution occurs shortly after 3-methylhistidine and it might be mistaken for 3-methylhistidine. 3-Methylhistidine has been found in muscle proteins (actin and myosin) but in these studies none has been found in the hot water extracts of muscle.

\section{DISCUSSION}

Although none of the results of the present research can be cited as evidence for a definite metabolic role for either anserine or carnosine, some interesting facts have been established. The values reported in the literature for the content of these dipeptides in a single muscle (the gastrocnemius muscle of the white rat for example) vary widely. Some of these differences may be explained by the inadequate analytical methods used in some of the earlier studies. The present study has shown that the ratio of anserine to carnosine in the gastrocnemius muscle of the white rat increases with age, limitation of food intake and the subcutaneous injection of hydrocortisone. The levels of anserine and carnosine in the gastrocnemius muscles of a group of rats of the same age and weight were essentially the same, although some of the rats were inactive, others relatively active and others received daily injections of thyroxin to stimulate their activity.

Nagai (1971) considers carnosine to be a cofactor in the defensive action of the cortisones. The experiment (Table 2) was planned to see if the subcutaneous injection of hydrocortisone would increase the carnosine level in the muscles of a rat. There was an increase in anserine and a decrease in carnosine in the muscles of the two groups of rats receiving hydrocortisone. The decrease in carnosine, however, was greater than the increase in anserine. It would be of interest to study the fate of this fraction of the carnosine.

Crush (1970) has discussed the various theories for the metabolic role of anserine and carnosine in striated muscles. Anserine and to a lesser degree carnosine are reported to be activators of the enzyme adenosine triphosphatase. The views of the Russian investigators, who have been interested in the role of anserine and carnosine for 40 years are briefly discussed in the paper of Severin \& Vulfson (1963). One role of these dipeptides is in the formation of energy rich phosphorus compounds. Their role as buffers in muscle as proposed by Davey (1960) is modified by Severin \& Vulfson (1963) to include a protective action on the mitochondrial structures. The results given in Table 3 which show a nearly constant level of anserine plus carnosine in cat muscles during long periods of stimulation gives support to this theory.
Severin \& Vulfson (1963) have presented evidence that the concentration of carnosine in frog muscles is greater in the more highly innervated areas. Carnosine is considered to be a mediator in neuromuscular transmission. In our attempt to repeat the work of Severin \& Vulfson (1963), it was found that an additional compound in frog muscle extracts was eluted with carnosine and histidine (method 1) giving high results for both. This work will be repeated with method 2, by which both carnosine and histidine are eluted without interference of the unknown compound.

Very few values for the anserine and carnosine content of human muscle appeared before 1968, when many of our samples were analyzed. Eighteen samples of human muscle obtained at autopsies and 32 samples taken during the course of surgery or by biopsy for microscopic studies were analyzed. Of the group of 18 , most of the persons were 50 years old, or older. The carnosine in $\mu$ mole $/ \mathrm{g}$ of muscle of the 72,74 and 88 year old individuals were $2.3,2.1$ and $1.1 \mu \mathrm{mole} / \mathrm{g}$. A 16 year old girl in this group had the highest level $(7.3 \mu \mathrm{mole} / \mathrm{g})$. The levels of carnosine per $\mathrm{g}$ for the remainder of the group ranged from 3 to $6 \mu$ mole.

The 32 samples taken at biopsy or during surgery were from individuals ranging in age from 3 months to 80 years. The $\mu$ mole of carnosine per $\mathrm{g}$ of muscle for (1) the younger group ( 3 months to 3 years); (2) teenage group; (3) the older group $(60-82 \mathrm{yr}$ ) were $1.5-2.5,4.9-8.3$ and 1.0-1.5, respectively. Anserine was not found in any of the samples.

It is tempting to correlate the levels of carnosine in a muscle with its ability to provide a strong, rapid response when required. Compare the reactions of a teenager with that of an 80 year old person. Consider also how a monkey with a carnosine level of $17-23 \mu \mathrm{mole} / \mathrm{g}$ of muscle can leap $20 \mathrm{ft}$ from a sitting position.

Acknowledgements-This research received support from Grant No. HD01233 from the National Institute for Child Health and Human Development, National Institute of Health, U.S.P.H.S. This is a grant to Halvor N. Christensen, to whom I am greatly indebted for allowing me to work in the department for 11 years after my retirement.

The author wishes to thank Thomas R. Riggs for help with the statistical work, P. O: Dennis, Brooke Bond Oxo Ltd., Croydon, England for a sample of $\beta$-alanyl-L-3methylhistidine; and Dr. Gerald D. Abrams, Department of Pathology for supplying post-mortem samples of human muscles.

\section{REFERENCES}

Casey K. L., Frommer G. P. \& Trefz B. R. (1974) Unpublished data.

Christman A. A. (1971) Determination of anserine, carnosine and other histidine compounds in muscle extractives. Analyt. Biochem. 39, 181-187.

CoHen B. J. \& Feldman D. B. (1968) Unpublished data. Crusit K. G. (1970) Carnosine and related substances in animal tissues. Comp. Biochem. Physiol. 34, 3-30. 
DAVEY C. L. (1960) The significance of carnosine and anserine in striated skeletal muscle. Arch. Biochem. Physiol. 89, 303-308.

DENNIS P. O. \& LoRKIN P. A. (1965) Isolation and synthesis of balenine, a dipeptide occurring in whale-meat extract. J. chem. Soc. 914, 4968-4972.

DuVigneaud V. \& Behrens O. K. (1939) Carnosine and anserine. Ergebn. Physiol. exp. Pharmakol. 41, 917-973.

Faulkner J. A., MaXwell L. C. \& Liberman D. A. (1972) Histochemical characteristics of muscle fibers from trained and detrained guinea pigs. Am. J. Physiol. 222, 836-840.

Huszar G. \& Elzinga M. (1971) Amino acid sequence around the single 3-methylhistidine residue in rabbit skeletal muscle. Bivchemistry 10, 229-236.

Johnson P., Harris C. I. \& Perry S. V. (1967) 3-Methylhistidine in actin and other muscle proteins. Biochem. J. 105, 361-370.

Koski J. Unpublished data.

Moore S., Spackman D. H. \& Stein W. (1958) Chromatography of amino acids on sulfonated polystyrene resins. Analyt. Chem. 30, 1185-1190.

Moore S., Spackman D. H. \& Stein W. (1958) Automatic recording apparatus for use in chromatography of amino acids. Analyt. Chem. 30, 1190-1206.

NaGAI K. (1971) Physiological implications of carnosine on the inflammation - with reference to the inhibitory action of allergy and the vital defense mechanism. $J$. Nihon Univ. Sch. Dent. 13, 1-11.

ONA T. \& Hirohata R. (1956) Synthese des ophidins. Hoppe-Seylers Z, physiol. Chem. 304, 77-81.

Perry T. L. et al. (1967) Carnosinemia-a new metabolic disorder associated with neurologic disease and mental defect. New Eng. J. Med. 277, 1219-1227.

Pocchiari F., Tentori L. \& Vivaldi G. (1962) The presence of the dipeptide $\beta$-alanyl-L-3-methylhistidine in whale meat extract. Sci. Rep. Int. Super. Sanita 2, 188-194.

Severin S. E. \& Vulfson P. L. (1963) The role of carnosine in neurotrophic relations. The Effect of Use and Disuse on Neuromuscular Function, (Edited by GutMan E. \& HNIK P.), pp. 53-62. Elsevier, Amsterdam.

Tallan H. H., Moore S. \& Stein W. H. (1954) Studies on the free amino acids and related compounds in the tissues of the cat. J. biol. Chem. 211, 927-939.

Tallan H. H. (1955) Free amino acids of muscles of normal and vitamin E deficient rabbits. Proc. Soc. exp. Biol. Med. 89, 553-555.

Zacharius R. M. \& Talley E. A. (1962) Elution behavior of naturally occurring ninhydrin-positive compounds during ion exchange chromatography. Analyt. Chem. 34, 1551-1556. 